\title{
REASONS AND REASONING IN EXPERT TESTIMONY
}

\author{
Albert S. Osborn*
}

In English and American law the testimony of witnesses is limited and weakened by many restrictions. This procedure is justified by tradition and precedent but much of it is not justified by common sense. An intelligent and honest witness is not permitted to make his testimony as effective and convincing as it might be made, as in France, for example, because of certain old rules formulated and fixed many generations ago by some old men wearing wigs, who have been very dead for many years. The controlling theory seems to have been that there is less danger of error with stories. half told than all told. It should of course be remembered that this procedure was developed in English law when only a few men on a jury, if any, could read and write, and most of them had never been out of the little county in which they were born.

These old crippling restrictions apply to all testimony, but in late years the limitations have been loosened somewhat, but not entirely, as applied to some phases of what in the law is described as expert testimony. This special testimony, if it is in fact what its name implies, is the statement of a conclusion, or series of conclusions, resulting from a course of reasoning, and this is especially true of all expert testimony based on a comparison of tangible things.

As is well known, a witness is described in the law as an expert because of his special knowledge and experience, but it does not always seem to be understood that when he expresses an opinion, that the opinion, with the informed witness, is based, not alone upon the specific evidence regarding the problem that is before him, but in some.measure also upon his own special knowledge and experience that in fact make him an expert.

Expert testimony on different subjects differs widely. A doctor may make an examination of a patient and express an expert opinion that the patient is permanently incapacitated. In many cases no helpful reasons can be given to an ordinary jury for such a conclusion. This is typical expert testimony. There are other classes of expert testimony, or what is called expert testimony, in which a qualified witness can explain to an intelligent hearer the basis or reasons for the opinion he

- Examiner of questioned documents since 1887. Author of Questioned Documents, (rgro, 2nd. ed. 1929); The Problem of Proof (I922). Contributor to legal periodicals. 
expresses. Testimony of this class is, in fact, the analysis and interpretation of circumstances and facts. The problems may be: Was a certain bullet fired from a certain gun? Were two finger-prints made from the same finger? Were a series of ransom notes in a kidnaping case written by an accused writer? Was a ladder made from lumber from a certain mill? Are two pieces of paper identical? Many other similar problems are encountered in civil and criminal cases.

A mere isolated fact often is an almost meaningless thing, but, when interpreted and explained, may spring into life and almost speak. Real circumstantial evidence is this language of things, and they often testify in a manner that cannot be successfully denied. The most forceful evidence in any court is this much criticised silent evidence of established facts when their relations and significance are clearly shown, but a mere statement of a fact may mean but little to the ordinary hearer. The most important part of expert testimony, when applicable, is of course this reasoning or "why" phase. The mind of even the ordinary man is eager to know the reasons for things and in many instances to understand is to be convinced.

As is well known, the ancient view of all expert testimony was that the expert's mere opinion was to be accepted or rejected wholly on the reputation and qualifications of the witness. This necessarily still is the rule-regarding those classes of expert testimony that are not susceptible of illustration and explanation so as to be weighed by the ordinary hearer. This is the class of testimony than can be rendered almost valueless in case of a conflict and in many instances deserves the severest criticism. A bare opinion is a dangerous basis for a verdict.

In this special testimony by an informed and experienced observer, in which facts and circumstances are interpreted, what may appear to be almost an off-hand opinion necessarily is the result of a definite course of reasoning. If the reasoning is not outlined and explained in any way the conclusion may seem to be merely an intuitive opinion, but this is not the fact. When, after careful observation, the witness expresses a formal opinion and then is permitted to outline in detail the reasoning process and steps leading up to the conclusion he has reached, he is then stating audibly what before was a silent mental operation. It is obvious that if an expert opinion is to be properly weighed and considered by the hearer, the reasoning process itself must be outlined as, otherwise, only the result or conclusion of the reasoning is expressed as in typical expert testimony.

This open oral reasoning operation, as a part of expert testimony, is necessarily, in effect if not actually in form, an argument tending to show to the hearer why the opinion is correct. That is its specific purpose. If correctly presented, this testimony analyzes, weighs and connects all the phases of the special evidence, shows their application to each other and to the problem in hand, and leads up to the final conclusion.

While nominally an expert is now permitted to "give reasons" for an opinion, in 
some courts he is not permitted to give definite, oral reasoning as a part of the actual testimony. Legal opinions, if not in direct conflict on this specific point, at least have not clarified the problem and have not clearly drawn the distinction between reasons and reasoning in expert testimony. The two classes of expert testimony, described above, are confused.

Many legal opinions, by inference at least, sensibly suggest that there is no distinction and that giving reasons for an opinion includes a presentation of the actual reasoning by which a conclusion is reached, while other legal opinions, and trial judges here and there, in their strict rulings hold that "giving reasons" does not include giving the course of reasoning itself. It is easily understood that this restrictive rule may greatly weakén testimony.

The exact question to be considered is to what extent are firearms, finger-print, wood identification, paper, handwriting and document experts, and other similar experts, to be permitted to outline in testimony the detailed, definite reasoning which has led to the opinion expressed. A clarifying legal annotation of this topic is now due. An Ohio opinion-fortunately not usually followed in actual trials even in Ohio-actually states that the evidence must be strictly confined to "what appears on the face of the document." This ruling in effect, if strictly enforced, makes the witness an ordinary witness and not an expert, and greatly weakens, if it does not completely destroy, the testimony. He cannot explain why the physical facts before him warrant a certain interpretation. The ruling holds that the interpretation of the facts does not come within "the four corners of the document." In some important cases this "four corners of the document" rule is strictly enforced.

The restriction of testimony of this class is undoubtedly partly based on the rule that an ordinary witness must not argue, and this detailed, and it may be very effective, reasoning by a witness in testimony as described, is so in contrast with the testimony of the ordinary witness that certain trial judges will not permit it to be given. They appear to be frightened by it. As administered, the rule often seems to be that the more convincing the testimony is, the more objectionable it becomes. Naturally justice may be defeated by the exclusion of testimony of this class.

It should also be better understood that the requirement that expert testimony should, if possible, always include the reasoning by which the conclusion is justified, is highly important, not only that correct testimony may be convincingly presented, but also in order that the frail and unsound basis of incorrect testimony may thus be directly exposed. The presumptuous, or corrupt, witness does not desire to expose the illogical reasoning by which he attempts to bolster up his incorrect opinion. The unqualified witness who testifies against the fact is, of course, unable to show a rational basis for his opinion. The intelligent judge may well say, "You have expressed your opinion but you have not given us the course of reasoning by which your opinion is justified." In the end the judge (at least in New Jersey and in the 
Supreme Court of Pennsylvania) may add, "Your opinion may be correct but your reasons to me are not cogent and are not convincing."

The restrictions on expert testimony are usually imposed as the result of objections, but there are some trial judges who, on their own initiative, prevent a witness from giving convincing expert testimony. Many of the objections by counsel have, however, been overruled over and over again by trial judges and courts of appeal, but they are still made.

The various objections presented are well known. Among them are: The testimony is objected to because it is merely argument; because the witness is "lecturing"; because the witness is not simply pointing out "facts appearing on the face of the document" but is "drawing inferences from the facts" and from his own-knowledge and experience; because the witness is "estimating the significance or force of the various facts to which he refers"; and finally, that "the witness is directly usurping the province of the jury" by answering "the very question that is to be submitted to the jury."2

Unfortunately there are attorneys on the right side of good cases who do not fully understand that reasoning by an expert witness is permissible, and they unknowingly hamper their own witnesses and sometimes not only weaken but in effect almost destroy the testimony. In these cases counsel, of course, are not prepared to make-even if they are disposed to make-the necessary arguments on the force and value of the testimony. As a result of this weakening procedure fraudulent claimants

${ }^{2}$ Henry's Estate, $276 \mathrm{~Pa}$. 5II, 5I4, 120 Atl. 454, 455 (I923): "It may not be amiss to add that the weight of opinion evidence on a question of handwriting depends on the cogency of the reasons given; here they do not appeal to us as convincing." (Jury verdict set aside.)

Magnuson v. State, 187 Wis. 122, 203 N. W. 749 (1925): "A rule of law that would permit an expert to take the stand and state his conclusion without doing any more would place the least qualified, most prejudiced expert on the same level as the best qualified and most conscientious expert. Particularly is this true in regard to the testimony of a handwriting expert, which rests very largely for its convincing power upon the similarities and peculiarities which enable the expert to arrive at his conclusion."

${ }^{2}$ Cropper v. Titanium Pigment Co., 47 F. (2d) $103^{8}$ (C. C. A. 8th, r93 I); Note (1932) 78 A. L. R. 737, 755: “. . . it is more important to get to the truth of the matter than to quibble over distinctions which are in many cases impracticable, and a witness may be permitted to state a fact known to him because of his expert knowledge even though his statement may involve a certain element of inference or may involve the ultimate fact to be determined by the jury." Per Gardner, J.

Dickenson v. Inhab. of Fitchburg, 79 Mass, 546, 555 (1859): ". . . they may readily perceive the force of his reasoning, the soundness or fallacy of his logic, and therefore, judge of his capacity to give an opinion on the subject, and the correctness of his conclusions, and consequently the weight due to his opinion." Per Shaw, C. J.

People v. Bird, 124 Cal. 32, 56 Pac. 639 (1899): “. . . but .I think that Gibson should have been permitted to state the grounds of an opinion (as to handwriting) to which he had testified, and am unable to appreciate the objection that it was argumentative."

State v. Dunn, 161 La. 532, 109 So. 56 (1926): "The witness was a highly intelligent and thoroughly trained expert. He was delivering his testimony in an orderly, clear and respectful manner, with no more 'lecturing' than was reasonably necessary.... It would have been valueless to the non-expert jurors without such explanation."

Cliff v. People, 84 Colo. 254, 269 Pac. 907 (1928): "Another assignment of error is that the trial court erred in permitting the people's witnesses 'to usurp the province of the jury' . . . The expert witnesses did not, and could not, usurp the province of the jury. The jury was at liberty to give to their testimony great weight, little weight, or no weight at all, depending upon all the facts and circumstances in evidence." 
succeed and the guilty escape. The attorney who is against the facts naturally favors all restrictions.

There is a common misapprehension regarding conflicts in expert testimony of the second class referred to above. Many lawyers glibly argue that expert testimony is "always in conflict." This is not true of much technical expert testimony. While there are witnesses who will testify on any case, and lawyers who will find and employ them, persuasive expert testimony is usually assailed by quoting old opinions, by bitter and exaggerated argument, by dependence upon the old rules and the favorable rulings of unprogressive trial judges, rather than by the presentation of opposing testimony. At least one technical 'expert witness is able to testify that in thirteen cases in succession there was no conflict.

Within the memory of many practicing attorneys a series of important progressive changes have been made in the legal rules and procedure regarding the admission of expert testimony in American courts. These changes have resulted from certain legal reforms and especially have resulted from the progress of science. All of these reforms regarding the admission of evidence have met vigorous opposition.

As in other legal fields, this opposition has been sincerely maintained by certain naturally conservative lawyers and judges, but this opposition has mainly come from that section of the legal profession whose success as lawyers is based upon the prevention of proof and whose main purpose and aim is the defeating of justice for their own profit and the profit of their clients. These are the men who fight for the old rules. In the old days these protesting and objecting men were greatly aided by the old restrictive legal procedure. The clan is not entirely extinct, and, sad to say, the aid is still given and cases are decided against the facts because of the restrictions.

In many trials resourceful defense and claim case attorneys make all the standard objections, which they know will be overruled, in order to create an unfavorable impression regarding the testimony and to interrupt and, if possible, annoy and embarrass a witness and break the continuity and force of the evidence. The purpose of this procedure is of course to prevent proof. It should not be permitted but it continues here and there. ${ }^{3}$

As is true in other fields, many expert testimony problems regarding disputed documents are, in some measure, problems in reasoning. "Why do you say that?" should be answered fully, clearly and explicitly if a hearer is to be led up to a rational conclusion. When testimony is improperly restricted it is, of course, impossible for anyone to say whether it is good or bad, and it then, as in the old days, becomes an appeal, not to the intelligence of a hearer, but simply to his credulity. This class of

\footnotetext{
"Venuto v. Lizzo, I48 App. Div. 164, I32 N. Y. Supp. 1066 (1911): "The conclusion of a handwriting expert as to the genuineness of a signature standing alone would be of little or no value, but supported by sufficiently cogent reasons his testimony might amount almost to a demonstration. While the court in this case did not directly refuse to allow the experts to state their reasons, as was done in the case of Johnson Service Co. v. MacLernon, 142 App. Div. 677, the effect of allowing constant trivial objections and of the erroneous rulings was virtually equivalent to such denial."
} 
testimony often is a shield for crime and an aid to fraud. There were formerly many judges who, by their rulings, made all expert testimony into this credulity testimony.

Correct, detailed, logical reasoning is necessary to show to technically untrained hearers the significance and force of the various details of evidence showing, for example, that a document was fraudulently written over a genuine signature, ${ }^{4}$ or to show that writing over a fold in the paper points to an unauthorized addition, or to show from the characteristics of crossed ink lines which was last made, or that a typewritten document was not all.written on the same machine.

The absolute necessity for reasoning regarding handwriting testimony, if it is to be effective, can be illustrated in many ways. There are, for example, many system qualities in handwriting, unknown to the ordinary observer, that are as distinctive as a German or Italian accent in speech, and a forgery may violate some of these fundamental qualities. If a witness is not permitted to show the history and significance of these qualities, then the most important and persuasive part of the testimony is excluded. 5

The modern and progressive conception of expert testimony regarding all these technical subjects is a common-sense and reasonable conception that requires a witness to give testimony so that its force or its weakness can be determined. It is, of course, true that if technical subjects of any kind are to be considered in a trial, then some knowledge of them should be possessed by those in charge of the matter, and if reasoned testimony is to be given this of course presumes technical knowledge and reasoning ability in the witness. Those who try cases of this kind who are ignorant regarding the technical subject will not know what is correct and what is incorrect, and the outcome may be a miscarriage of justice. Uninformed witnesses sometimes give incorrect and misleading testimony that is not properly attacked be-

'Brant v. Dennison, et al, 5 Atl. 869 (Pa. 1885): "The alleged assignment bears upon its face indications of its having been written over an existing signature. . . . In all such inquiries great latitude in the admission of testimony is neither unreasonable or improper."

Dubois v. Baker, 30 N. Y. 355 (1864): "The object was to show that the note was not written in the defendant's usual manner, but the letters were smaller and more crowded; the plaintiff thereby intending to satisfy the jury that the note was written over a signature of the intestate and was not a note signed by him. . . . It was competent to prove this fact."

${ }^{5}$ Dougherty v. Milliken, 163 N. Y. 527, 57 N. E. 757 (I900): "It may be broadly stated as a.general proposition that there are two classes of cases in which expert testimony is admissible. . . If the knowledge of the experts consists in descriptive facts which can be intelligently communicated to others not familiar with the subject, the case belongs to the first class. If the subject is one as to which expert skill or knowledge can be communicated to others, not versed in the particular science or art, only in the form of reasons, arguments or opinions, then it belongs to the second class."

In re Varncy, 22 F. (2d) 230, 237 (E. D. Ky. 1927): "As to the testimony of the five bankers, relied on by the claimants, it is greatly weakened by the consideration that not one of them gave a reason for the faith that was in him. . . . I was entitled to have the basis of the opinons of these bankers in order that it might test their soundness, and this has not been afforded me. I never like to follow anyone blindly." Per Cochran, J.

Pioneer Coal Co. v. Polly, 208 Ky. 548, 271 S. W. 592 (1925): "They testified, in substance, that the decedent's signature on the register was not written by him, according to their opinion. They referred to no fact nor pointed out any reasons for their statements and left their flatly stated opinion unaided by the statement of any fact to enable either the court or the jury to draw a legal conclusion as to the accuracy of their testimony, or its probative effect." 
cause there is no one present, no witness, lawyer, or judge, who knows whether it is good or bad. When the blind leads the blind they may both fall into the ditch.

The foregoing discussion forcibly suggests that unqualified witnesses should not be allowed to testify as experts. Hundreds of alleged experts testify who should not be permitted to testify. If the witness cannot weigh or estimate the force and significance of the evidence upon which a conclusion is based, then his opinion is not an expert opinion but is a mere conjecture of a dangerous character. Much testimony of this kind is given that should not be received in any court. It is very seldom that the testimony of an alleged expert of any class is excluded, no matter how stupid or incompetent he may be. In many instances he is no better qualified to give an opinion on the subject under inquiry than any intelligent juror. This fact should be brought out in some manner.

The "qualifying of an expert" is a performance which is supposed to prove to the judge that the witness offered is in fact an expert. This procedure in many American courts has become a mere formality that precedes the presentation of expert testimony by anyone who assumes to be an expert or whom the lawyer presents as an expert. Stricter rules would prevent the advocate against the fact from bringing into court any old dead cat of an expert that he has found in a back alley. It usually is not a lack of legal right, or lack of courage, in the judge that allows almost anyone to testify as an expert, but an act in conformity with an almost universal custom.

It would no doubt contribute to justice if the requirement was made that a written statement of a proposed expert's qualifications should be presented to the presiding judge in advance of the trial so that his qualifications, his record and experience could be carefully investigated. Like the new law regarding advance notice of a proposed alibi, this requirement would promote justice by limiting expert testimony.

The alleged expert witness also should always be properly cross-examined, which of course is impossible if counsel is unassisted or technically unprepared. It raturally follows that those who conduct trials should have some information on the subjects considered in those trials, or decisions should not be based on the technical testimony alone.

Finally, and perhaps most important of all, the informed, fair and unprejudiced judge, with power to participate and assist in a trial, is the most important performer in a trial court if technical testimony is to be properly presented and correctly weighed. There are more of these judges than there were, and there will be more of them than there are. 